\title{
Așırı Turizm, Nüfus Teorisi ve Turizme Katılım
}

\author{
İlker GÜL \\ Bahçeşehir Üniversitesi \\ ilker.gul@sad.bau.edu.tr \\ ORCID: 0000-0002-8042-5070 \\ Dilistan SHIPMAN \\ Bahçeşehir Üniversitesi \\ dilistan.shipman@sad.bau.edu.tr \\ ORCID: 0000-0001-9829-960X
}

\begin{tabular}{lrr} 
Derleme Makale & DOI: $10.31592 /$ aeusbed.827987 \\
\hline Geliş Tarihi: 18.11 .2020 & Revize Tarihi: 29.07 .2021 & Kabul Tarihi: 27.09 .2021
\end{tabular}

\section{Atıf Bilgisi}

Gül, İ. ve Shipman, D. (2021). Aşırı turizm, nüfus teorisi ve turizme katılım. Ahi Evran Üniversitesi Sosyal Bilimler Enstitüsü Dergisi, 7(3), 993-1006.

\section{ÖZ}

Talep yüksekliğinin yarattığı yoğunluk önceden beri var olan bir sıkıntı olarak düşünülse de günümüzde net görülebilir, somut bir sorun haline gelmiştir. Genel olarak çözüm önerileri tanıtımı kesmek, kota koymak, turist sayılarında azaltmaya gitmek ve turistlerin daha az yoğun turizm duraklarına dağıtılması olarak öne çıkar. Ancak genel talep artışı devamı kaçınılmaz gözükmektedir. Bu, Malthus'un nüfus teorisine benzerlik gösterir. Daha çok besin daha çok nüfus getirir, daha çok nüfus daha çok besin gerektirir, ancak üretilebilecek besin miktarı bellidir ve bu sınır aşılamaz. Turizmde ise nüfus artışı ve diğer etmenler turizm talebini yükseltir. Yüksek talep ve aşırı turizm daha çok turizm durağını gerekli kılar. Durak memnuniyeti ve artan nüfus, talebi daha fazla besler ve yeni arz, turizm durakları, gerektirir. Ancak bu arzın sonsuza kadar sağlanması ya mümkünsüzdür ya da nihayetinde Dünya'daki her bir lokasyonun bir turizm durağına çevrilmesiyle mümkündür. Ancak ikinci seçenek hem sosyal hem de ekolojik dengeler için uygulamada sorunludur. Çalışma kavramsal bir çerçeve öne sürerken küçülmenin tek muhtemel çözüm olduğu sonucuna varmaktadır.

Anahtar Kelimeler: Malthus'un sınırı, sürdürülebilir turizm, turizm talebi, aşırı turizm.

\section{Overtourism, Theory of Population and Demand for Tourism}

\begin{abstract}
Although the crowded created by the high demand is considered as a problem that has existed long before, it has become a clearly visible problem today. In general, suggestions for solutions de-promoting, limitation, reducing the number of tourists and distributing tourist demand to less intense tourism destination. However, the continuation of the general increase in demand seems inevitable. This is same as Malthus' theory of population. More food brings more population, more population requires more food, but the amount of food that can be produced has a limit and this limit cannot be crossed. In tourism, population growth and other factors increase the demand for tourism. High demand and over tourism require more tourism destination. Destination satisfaction and growing population feed demand further and require new supply, tourism destinations. However, it is either impossible to provide this supply forever, or it is possible by turning every location in the world into a destination. However, the second option is practically impossible for both social and ecological balances. While the study suggests a conceptual framework, it concludes that degrowth is the only possible solution.
\end{abstract}

Keywords: Malthusian limit, sustainable tourism, tourism demand, overtourism.

\section{Giriş}

Aşırı turizm bugün gerçek bir sorundur. Milano, Cheer ve Novelli (2019, s. 2) aşırı turizmi "ziyaretçi sayısındaki aşırı artışın kalabalıklara yol açtığı, sakinlerin geçici ve sezonluk olarak zirvelerin sonuçlarından zorluklar yaşadığı yerlerde, bunların da yaşam şekillerinde kalıcı değişiklere yol açtı̆̆ı, yerel olanaklara ulaşımının azalması ve iyi oluş halinde genel bir azalma" olarak tanımlar. Sorun kalıcıdır ve giderek artış gösterme eğilimindedir (Dodds ve Butler, 2019a). Bu eğilim talebin kalıcılığına paraleldir. Turizm talebi ve turistlerin yarattığı sıkıntılar önceden de mevcut olmasına rağmen bu sıkıntılar devamlı sorunlar haline dönüşmüştür. $\mathrm{Bu}$ yüzden aşırı turizm tüm turizm durakları için bilinen bir görüngü haline getirmiştir. Aşırı turizm, duraklarının genişlemesi, yayılması 
ve yenilerinin oluşturulması yoluyla çözülmeye çalışırken bir ikilem yaratmaktadır çünkü talep yine mevcuttur, kalıcıdır.

Nüfus artışı ve onun yarattığı sorunlar da turizm talebi artışının yarattığı sorunlara paralel olarak düşünülebilir. Nüfus artışı ve onun yaratacağı sorunlar üzerine çeşitli nüfus teorileri ortaya atılmışken içlerinden en çok tartışma yaratan Robert Thomas Malthus'un teorisi olmuştur (Caldwell, 1998; Duvick, 1999; Price, 1998; Smith, 2015; Trewavas, 2002; Wrigley, 1988). Malthus'un teorisinin temeli nüfus ve besin üretiminin ilişkisi üzerine kuruludur. Malthus'a (2017) göre besin artışı nüfus artışını besleyecektir, nüfus artışı da daha çok besin üretimi artışını gerekli kalacaktır. Ancak bunun sonsuza kadar devam etmesi mümkün değildir. Çünkü Dünya'nın kaynakları sınırlıdır. Besin üretilebilecek toprak yüzölçümü bellidir. Nüfus artışının durmaksızın devam etmesi halinde, besin üretimi kendi sınırına ulaşacak ve durmak zorunda kalacaktır. Buna Malthus'un sınırı denilmektedir (Corry, 1959, s. 718). Bu sınırın geçilmesi halinde ise nüfus açısından birçok sorun (açlık, sınıfsal çekişmeler, iş gücü ve genel ekonomik yapıda bozulma vb.) ortaya çıkacaktır.

Aşırı turizm ve Malthus'un nüfus teorisi birbirine benzer çıkmazlara gitmektedir. Besin üretiminin de turizm durağ 1 ve kapasitesinin de sonsuza kadar artması düşünülemez. Aksine bir noktadan sonra artışlar kendilerini besleyen kaynaklara, doğal ve iktisadi sisteme, nihayetinde nüfusa zarar verecektir. Bu benzerlikler sebebiyle, yapılan bu kavramsal çalışma nüfus artışı, turizme katılım ve aşırı turizm sorununu Malthus'un nüfus teorisi kapsamında ele almayı amaçlamıştır. Malthus'un nüfus teorisinin bakış açısıyla artan nüfus ve turizme katılım grafikleri açıklanmaya çalışılmıştır. $\mathrm{Bu}$ grafik ve verilerden çıkarımlar yapılmaya çalışılmıştır. Dünya nüfus artışı ve turizme katılımın artmaya devam etmesi durumunda aşırı turizmin normal sıradan bir hal alacağ düşünülmüştür. Sürdürülebilir turizm çalışmalarının ise yeniden değerlendirilmesi gerekecek ve gerçekten sürdürülebilir olup olmadığı sorgulanacaktır. Sürdürülebilirlik faaliyetlerinin sürdürülebilirlikten ziyade öteleme kavramına dönüşmesi kuvvetle muhtemeldir.

\section{Turizm Durakları ve Aşıırı Turizm}

Turizm hareketleri yarattı̆̆ 1 döviz geliri, istihdam ve kalkınma sebebiyle ülkeler tarafından arzulanmakta ve amaçlanmaktadır (Buluk ve Eşitti, 2019, s. 169; Çetin, 2017, s. 45). Hareket turizm duraklarına doğru yönelir. Turistler burada turizm faaliyetini kendileri için kurulmuş ticari bir sistem çerçevesinde gerçekleştirir. Ancak bu sistem tamamen bağımsız değildir. Çoğu zaman ya kısmen ya da tamamen yerel halkın olanaklarına entegredir veya kullanılan aynı imkân ve tesislerdir (Dodds ve Butler, 2019b, ss. 523-524). Bu ev sahibi ülke açışından bir avantaj olarak görülmüştür; çünkü fazladan bir yatırım yapmadan hali hazırdaki alt ve üst yapı kullanılarak turizm geliri edilmesi uygulamada mümkündür. Turizm birçok durak tarafından ekonominin canlandırılması amacıyla düşünülürken çok az kontrol edilmesi gereken bir şey olarak düşünülmüştür (Avond vd., 2019, s. 553; Akt. Page, 2011, s. 339). Bu sebeple zamanla turist kalabalıkları yerel şehir sakinlerinde rahatsızlıklar yaratmaya başlamıştır.

İlk bakışta basit ve sıradan gözüken bu işleyiş günümüzde turizm duraklarında artarak yoğunlaşmaktadır. Artan talep belli noktaların popülerlik kazanmasına sebep olurken yoğunlaşmayı beslemiştir. $\mathrm{Bu}$, kısaca aşırı turizm olarak ifade edilebilir. Goodwin $(2017$, s. 1) aşırı turizmi, ev sahiplerinin veya misafirlerin, yerlilerin veya ziyaretçilerin, birçok ziyaretçi olması ve bunun bölgedeki yaşam kalitesinin veya deneyim kalitesinin kabul edilemez derecede kötüleşmesi sebebiyle mutsuz olması, olarak tanımlar. $\mathrm{Bu}$ mutsuzluğun doğrudan turizm dură̆ olan bölgenin yabanc1 kimselerle kalabalıklaşmasına yönelik bir mutsuzluk olduğu anlaşılabilir. Bu kalabalıklaşma fiziksel taşıma kapasitesini zorladığı gibi, bölgenin toplumsal/psikolojik kapasitesinin de zorlandığı anlamına gelmektedir. Doxey'in (1975) turizm duraklarının üzerine çalışması bir tolerans modelini sunar. Bu model turizm durağının gelişim sürecinde halkın tepkisini açıklar. Model ilk aşamada mutluluk, sonrasında gelen ilgisizlik, turist sayılarının artmasıyla kızınlık/öfke ve en son noktada düşmanlık/kin/nefret halini yerlilerin tutumu olarak önerir (Çetinkaya ve Dedemen, 2013, s. 28). Ancak Doxey'in (1975) tolerans modelinin son aşaması turistik durağın büyümesinin durduğu anlamına gelmez. Yılmaz ve Filiz (2017, s. 1805) Butler'ın turizm durakları yaşam eğrisini Doxey'in 
tolerans modeli ile eşleştiren Tablo 1'i oluşturmuştur ve bu tablo talebin devam edebileceğini göstermektedir.

Tablo 1

Doxey ve Butler'ın Modellerinin Eşleştirilmesi

\begin{tabular}{lll}
\hline $\begin{array}{l}\text { Duygu Düzeyi } \\
\text { (Doxey, 1975) }\end{array}$ & Tepkiler & $\begin{array}{l}\text { Muhtemelen } \\
\text { Aşamalar } \\
\text { (Butler, 1980) }\end{array}$ \\
\hline Mutluluk & $\begin{array}{l}\text { Varış yerinin gelişmesinin ilk aşaması ile ilişki, heyecan, beklenti ve } \\
\text { turistlerle gayri resmi iletişim }\end{array}$ & $\begin{array}{l}\text { Keşif } \\
\text { Katılım }\end{array}$ \\
İlgisizlik & $\begin{array}{l}\text { Turistlerle daha resmi temas, turistleri gelir ve yatırım kaynağı olarak } \\
\text { görme }\end{array}$ & Gelişim \\
Öfke/Kızgınlık & $\begin{array}{l}\text { Artan fiyatlar, diş yatırımlar ve altyapı nedeniyle yerel halkın } \\
\text { endişeleri görülmeye başlanır }\end{array}$ & $\begin{array}{l}\text { Pekişme } \\
\text { Durulma }\end{array}$ \\
Kin/Nefret & $\begin{array}{l}\text { Kizgınlık sözlü ve giziksel olarak ifade edilir ve turistler tüm } \\
\text { sorunların kaynağıdır }\end{array}$ & $\begin{array}{l}\text { Yeniden Canlanma } \\
\text { Düşüş }\end{array}$ \\
\hline
\end{tabular}

Doxey (1975) ve Butler (1980)'den uyarlayan Yılmaz, Ö. D. ve Filiz, A. (2017). Turizm gelişim yaklarşımları kapsamında yerel halkın turizme yönelik algı ve tutumları: Mazi Köyü-Türkbükü karşılaştırmalı analizi. Hitit Üniversitesi Sosyal Bilimler Enstitüsü Dergisi, 10(2), 1799-1824.

Butler'ın (1975) yaşam eğrisinin son aşaması iki seçenek sunar ki bunlardan biri yeniden canlanmadır. Yeniden canlanma, turist talebinin mevcut turizm durağında canlanması/artmas1 anlamına gelmektedir. Düşüş seçeneğinin turistik yoğunluğu azaltacağını düşünebilecek olsak da düşen talebin aslında başka bir yere, turizm durağına, kaydı düşünülebilir. Bu bulgular iki önerme ve çözüm ortaya çıkarır. İlki mevcut turizm durağına talep yükselişinin sebep olduğu toplumsal/psikolojik durumun Doxey tolerans modelinin son aşamasının ötesine geçmesi ve turizm gelirle fiziksel altyapının artırılmaya çalışılmasıdır. Ancak bu sadece fiziksel bir çözüm içermekte ve psiko-sosyal durumu çözümsüz bırakmaktadır. İkincisi ise talebin başka bölgelere kaydırılarak yeni turizm duraklarının yaratılması veya mevcut olanların Butler'ın modeline benzer şekilde büyütülmesidir; ta ki ilk yaptığımız önermeye dönene kadar. Sonra kısır bir döngü olarak yeni turizm durakları yaratılmak zorunda kalınacaktır.

Duraklar, turist talebi ve memnuniyeti üzerine çalışan birçok araştırmacı aşırı turizmi öngörmüştür. Buna paralel olarak sorunu önüne geçme, çözme veya geciktirme amaçlı araştırmalar (Avond vd., 2019; Bourliataux Lajoinie, Dosquet ve del Olmo Arriaga, 2019; Ceron ve Dubois, 2007; Dodds ve Butler, 2019a) gerçekleştirmiştir. Çalışmalar aşırı turizm görüngüsünün yarattığı sorunlar temelinde farklılık göstermektedir. Ceron ve Dubois (2007) gibi çalışmalar farklı senaryolarda çevresel etkiler ve sera gazı salınımı üzerine odaklanmıştır. Bourliataux Lajoinie vd., (2019) gibi çalışmalar sorunu besleyen durumlar üzerinde durmaktadır. Dodds ve Butler (2019a) gibi çalışmalar ise sorunun önüne geçmeye yönelik stratejileri ve yerel halkın durumuna etkisini tartı̧maktadır. Koens, Postma ve Papp (2018) da önerdiği üzere aşırı turizmin karmaşıklığı tekrar ortaya çıkmaktadır. Öyleyse turizmin talebini besleyen kanallar ve ortaya çıkan görüngünün yarattığı sonuçlar da çeşitlilik gösterir.

Turizm talebi sürekli artışının sebepleri alanyazında farklılık gösterir ki bu çeşitlilik haklı gerekçelere dayanmaktadır. İkinci Dünya Savaşı'ndan sonra batı bloğundaki ülkelerin liberal hayat tarzıyla bütünleşmesi, soğuk savaşın bitişi ve Sovyetler Birliği'nin çöküşü ile dünyanın hareket özgürlüğü anlamında küreselleşmesi tamamlanmıştır ve alternatifsiz hale gelmiştir (Uğur ve İzgi, 2011, s. 158). Ulaşım imkânları ve teknolojideki gelişmeler insanların seyahat etmelerini daha kolay hale getirirken turizm endüstrisinin gelişimi için de uygun zemin yaratmıştır. Bilim, onun yarattığı bilginin teknik bilgiye dönüşümü gerekli teknolojik altyapıyı oluşturmuştur. Teknoloji ve bilginin dijitalleşmesi hem tedarik sürecinde hem de durak seçiminde çok etkin bir konuma gelmiştir (Bourliataux Lajoinie vd., 2019, s. 587; Jacobsen Munar, 2012; Sigala, Rahimi ve Thelwall, 2019). Tabi ki bu gelişmelere sosyal haklarda ve genel hayat kalitesinde gelişmenin eşlik ettiğini unutmamak 
gerek. Tüm bunların birleşimi, turizm talebi de sürekli bir artışa sebep olmaktadır; Grafik 1 ve 2'de uluslararası ziyaretçi artış oranı ve sayısı sırasıyla görülebilir.

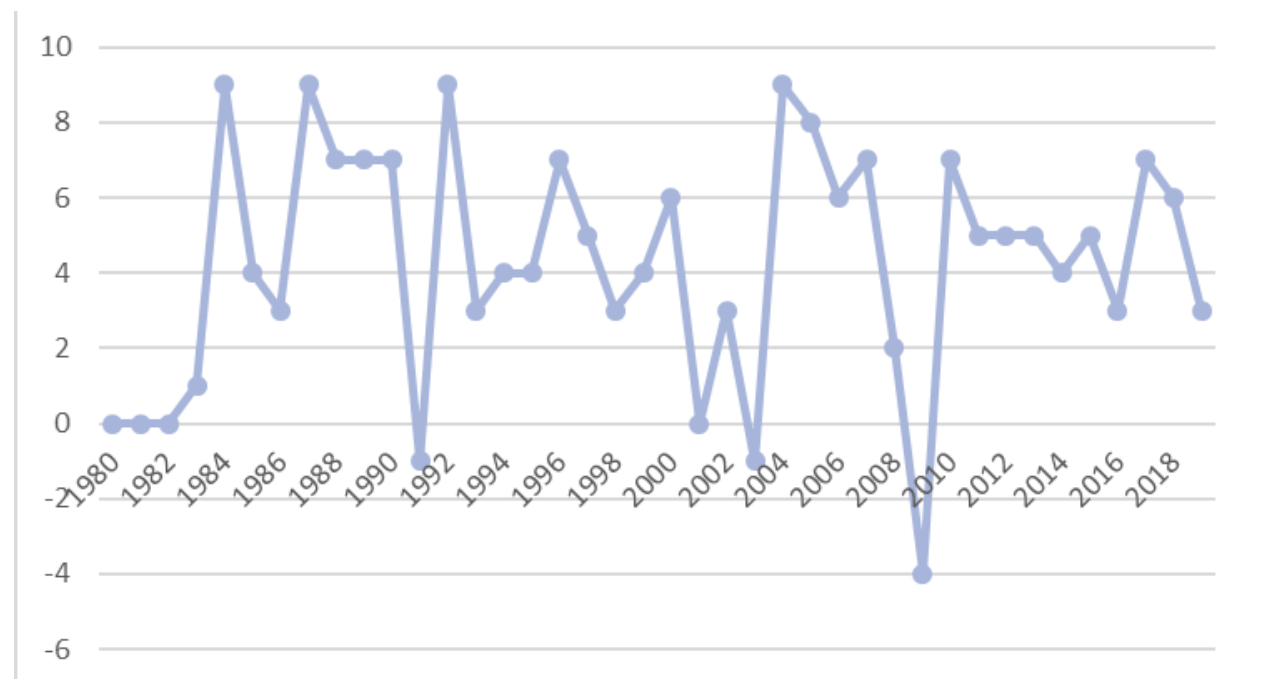

Grafik 1. Y1llara Göre Uluslararası Ziyaret Artış Oranları (\%) (United Nations World Tourism Organization. (2020). Global and regional tourism performance| UNWTO.

https://www.unwto.org/global-and-regional-tourism-performance adresinden 21.09.2020 tarihinde erişilmiş̧ir.)

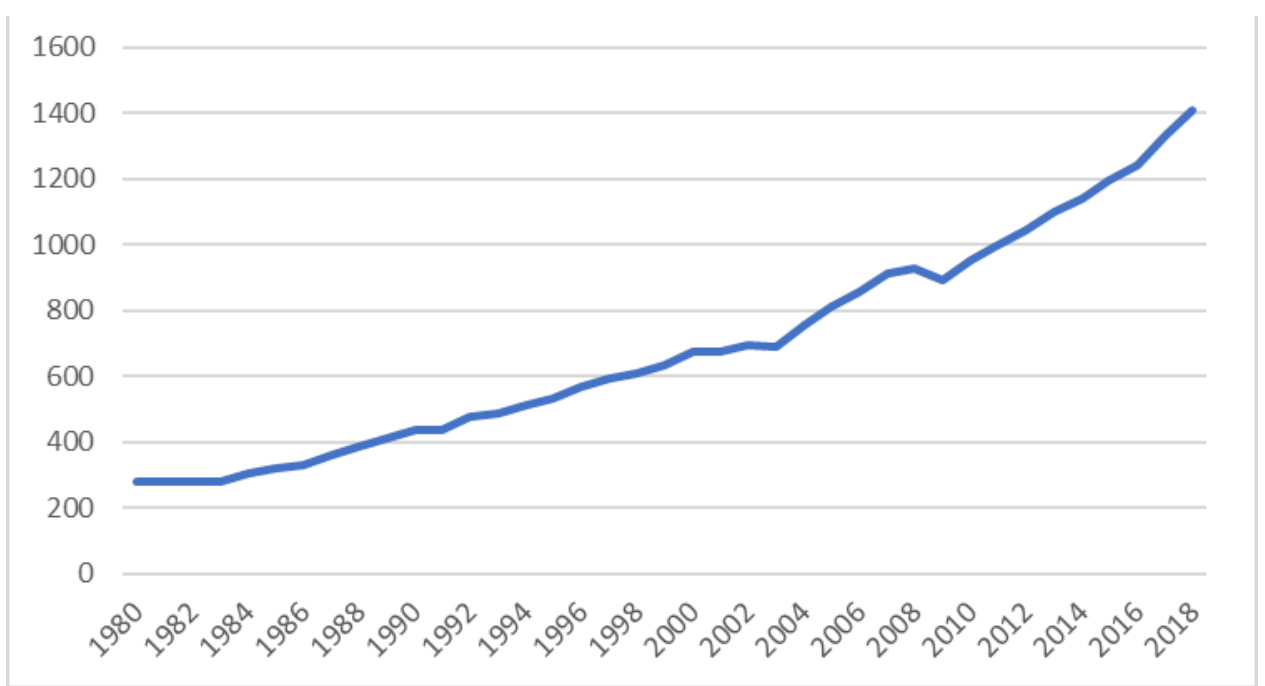

Grafik 2. Yıllara Göre Uluslarası Ziyaret Artışı (milyon) (United Nations World Tourism

Organization. (2020). Global and regional tourism performance| UNWTO.

https://www.unwto.org/global-and-regional-tourism-performance adresinden 21.09.2020 tarihinde erişilmiş̧tir.)

Grafiklerde görüldüğü üzere talep 2008'de olduğu gibi kriz dönemleri hariç sürekli bir artış göstermektedir. Grafiklerde talep hep yukarı yönlüdür. Artan talebin özellikle belli duraklarda yoğunlaşmasıyla aşırı turizm denen görüngü ortaya çıkmıştır. Dodds ve Butler'ın (2019b) belirttiği gibi aşırı turizm eski bir sorun için yeni ifadedir ki belli bir durak için turist akışının yerel halka olan tüm olumsuz etkilerini ifade eder. Dodds ve Butler'a (2019b, s. 523) göre sosyal medya, yapılacaklar listesi (bucket list), ölmeden önce görülmesi gereken yerler gibi listelerle bu noktaların ziyareti için baskı yaratmaktadır. Bu da talebin yoğunlaşmasına sebep olmaktadır. Bunun yanı sıra turizm endüstrisinde yerel ve ulusal hükümetlerden bağımsız olarak tanıtım ve pazarlama faaliyetlerinin yapılması, düşük maliyetli havayolu şirketlerinin artması, airbnb, uber gibi dijital platformları turizm imkânlarına ulaşımı kolaylaştırması ve ucuzlatması, turzim acentalarının tanıtım faaliyetleri ve kampanyalarında turizm durağının tanıtılması talebin yükseltilmesine sebep olmaktadır. Dodds ve 
Butler'a göre (2019b, ss. 523-524) yoğunlaşan talep yerel halkın günlük yaşantısında kullandığ1 imkânlara ulaşmasında zorluklara, turist enflasyonuna sebep olur. Sæbórsdóttir, Hall ve Wendt'e (2020, s. 4) göre Airrbnb gibi dijital platformlar sebebiyle konut bulamamalarına ve araç trafiğine yol açmaktadır.

Turizmin ekonomiye olan faydaları sebebiyle turizm durağı yönetim organları turizmi yönetmek yerine turist sayılarını artırma ve bu şekilde gelirlerini en üst seviyeye çıkarmayı amaçlamışlardır (Dodds ve Butler, 2019b, s. 521). Bu düşünce tarzının sonucu olarak turist sayıları yükselmiş ve paralel olarak gelirler de yükselmiştir. Ancak birlikte gelen sorunlar genelde göz ardı edilmiştir. Alanyazındaki tutulan çözüm önerileri şu şekilde sıralanabilir:

- İndirgeme (demotion)

- Sinir koyma (limitation)

- Caydirma ve engel koyma

- Yoğunluğu dağıtmak, turistleri daha az yoğun turizm duraklarına yönlendirmek

Avrupa'nın Amsterdam, Paris, Barselona, Venedik vb. turizm duraklarında artan yoğunluk ve düşen yerli hayat kalitesi tartışmalar başlatmıştır. Amsterdam çözümün bir yolu olarak indirgemeye gitmeyi görmüştür ve şehir politikasının bir parçası haline gelmiştir (Dodds ve Butler, 2019b, s. 524). Ancak burada amaç Amsterdam'ı turistler tarafından istenmeyen bir yer haline getirmek değil; büyük kalabalıklar için tanıtmamak (promote etmemek) olduğunu gözden kaçırmamak gerek (Dodds ve Butler, 2019b, s. 524). Bu sayede durağa darbe vurmak yerine sadece turist kalabalıkları azaltılmak istenmekte ve turist karşıtı bir duruş sergilenmemiş olmaktadır.

Diğer çözüm şekli olarak görülen limit koyma ise daha turist karşıtı bir seçenek olarak karşımıza çıkmaktadır. Ancak ilk aşamada şehir girişlerine limit koymak yerine şehirlerin içinde aşırı yoğunlaşma olan yerlere turnikeler koyularak deneysel bir uygulama Venedik şehrinde yapılmıştır (Deutsche Welle [DW], 2018; Sky News, 2018). Bu turnikeler kalabalık meydanlar ve şehir içi yaya köprülerindeki yaya trafiğini ve kalabalığı kontrol ederken şehir sakinleri ve kentin tahsis ettiği kartı olanlara geçiş imkânı vermesi planlanmıştır (DW, 2018; Sky News, 2018). Venedik örneğinin bir sonraki adımı şehirlere giriş çıkışta benzer uygulamalara gidilmesi olarak düşünülebilir ancak bu seyahat serbestliği ve özgürlüğü gibi temel haklarla çatışmaya (Perkumienė ve Pranskūniené, 2019) yol açacaktır.

Aşırı turizmi besleyen kaynaklar arasında seyahat ve konaklama maliyetlerinin düşmesi görülmektedir. Ulaşım (düşük maliyetli havayolları), konaklama (airbnb) gibi seçenekler turizmi ucuzlatarak daha geniş kitlere yaymıştır (Nepal ve Nepal, 2019, s. 10; Roncak, 2019). Bazı ulusal ve yerel hükümetler vergilendirmeyi turizmi yönetmede bir araç veya aşırı turizmi bir araç olarak kullanmayı öngörmüştür (Nepal ve Nepal, 2019). Bu sayede maliyet temelli engel koyarak caydırma ve turist sayısında azalma amaçlanmaktadır. Ancak bunun bir çözüm olup olmadığı tartışmalıdır; daha bütünleşik geniş kapsamlı çözümler üretilmediği sürece aşırı turizmle karşılaşmak kaçınılmazdır (Nepal ve Nepal, 2019).

Son olarak gerek akademi gerek sahada en çok önerilen ve uygulanan yöntem ise turistik talebin farklı sezonlara ve farklı lokasyonlara yayılarak yeni turizm duraklarının geliştirilmesidir. $\mathrm{Bu}$ şekilde hem aşırı turizm sorunundan uzak durulması, hem turizm gelirinin artırılması ve ülkenin diğer kesimlerinin de turist harcamalarından payını alması amaçlanmaktadır. Türkiye'nin 2023 Turizm Eylem planı bunun harika bir örneğidir (T.C. Kültür ve Turizm Bakanlığı, 2013). Ancak bu ülkeye olan toplam talebi artıracaktır. Çünkü talebin durdurulmasından ziyade farklı bölgelere de dağıtılması amaçlanmaktadır. Belli bir turizm durağı temelinde düşünürsek Paris'e gelen turistlere Eiffel Kulesine, Louvre Müzesine gitmemelerini söyleyip başka yerleri tanıtmaya çalışmak başarılı olmayacaktır.

Görüldüğü üzere çözüm önerileri aşırı turizmi çözmekten ziyade sorunu geçici olarak durdurmayı, başka alanlara dağıtarak ertelemeyi veya durak içinde memnuniyetsizliği yaratan aşırı 
kalabalığı sınırlamayı amaçlamaktadır. Önerilen çözümler sorunun varlığının kalıcı olduğunun göstergesidir. Öneriler sorunu ortadan kaldırmaktan uzaktır.

\section{Malthus'un Nüfus İlkesi}

18. yüzyılın sonu 19. Yüzyılın başı Dünya ve İngiltere için önemli bir devrimi işaret eder; Sanayi Devrimi (Malthus, 2017, s. 7). Bu dönem, insan toplumunun işleyişinin ve sosyal hayatın kökten değiştiği yenilikler içermektedir. İnsanlığın üretme yeteneklerinde yöntem değişikliği (makinelerin ve buhar enerjisinin kullanımı) insanlığın geleceğine dair soruları da beraberinde getirmiştir. Bu sorular insanlığın artık her şeye muktedir olduğu ve zenginliğin toplumu beklediği fikirlerine karşılık ortaya çıkmıştır. Malthus bu soruları tartışan kimselerin başında gelmektedir. Onun tartışmalar yaratan ilkesi şu varsayımlar üzerine temellenir (Malthus, 2017, s. 29):

- Beslenme insanın var olabilmesi için zorunludur.

- Cinsiyetler arasındaki tutku zorunludur ve gelecekte neredeyse şimdikiyle aynı şekilde kalmayı sürdürecektir.

$\mathrm{Bu}$ varsayımlar üzerinden insanlığın nüfusundaki artış hızının, besin üretme miktarındaki artışı giderek katlayacağı ve sonunda bir açmaza gireceğini önermektedir. Bir sınıra geldiğinde besin ve nüfus başa baş olacaktır. Ancak Malthus'un sınırı denen bu sınır aşıldığında artık besin yetersiz kalacaktır (Grafik 3). Dolayısıyla ikisinin paralel ilerleyişi uzun süre mümkün değildir. Bir noktada üretilen toplam besin nüfusu beslemeye yetmeyecektir.

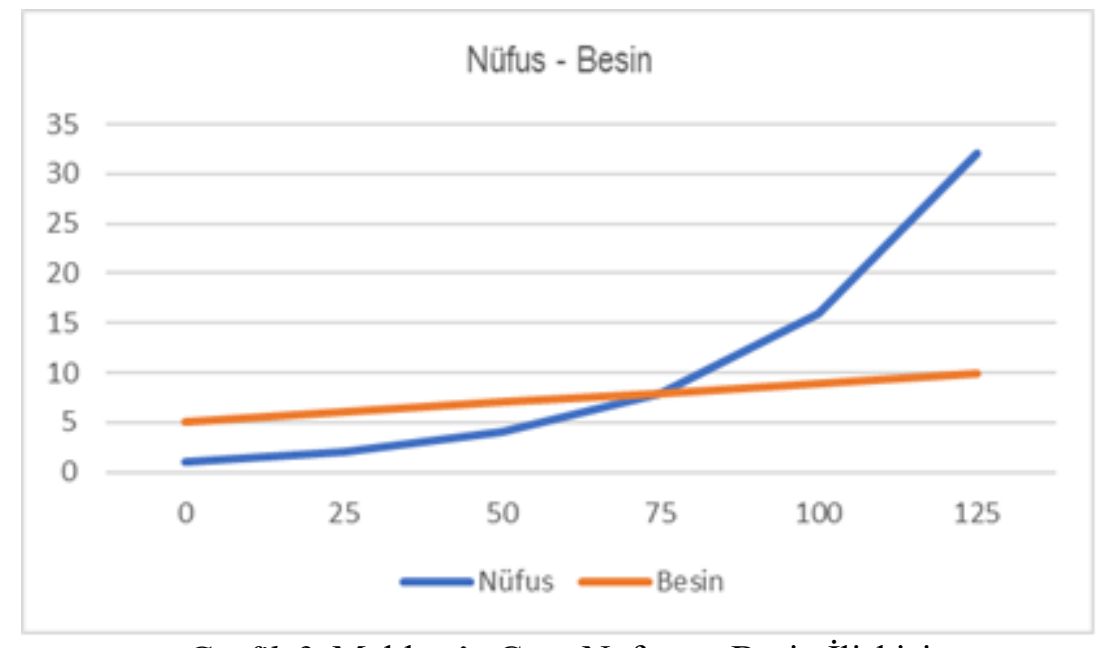

Grafik 3. Malthus'a Göre Nüfus ve Besin İlişkisi

Sınır aşıldıktan sonra savaşlar, çatışmalar, toplumsal kargaşa ve hastalıklar insan nüfusunu azaltamaz ise kıtlıklar insanların ölümüne sebep olacaktır. Bu öngörü zenginlik ve bolluk atfedilen geleceğe dair karanlık bir tablo çizmiştir. Çokça eleştiri almış ve teknolojideki gelişmeler sayesinde öngörüsünün gerçekleşmediği ortaya konmuştur (Smith, 2015; Trewavas, 2002). Ancak Malthus'un öngörüsünün geçmiş için yanlış çıkması veya birtakım yeniliklerle (yeşil devrim 1940-70, biyolojik, ucuz enerji, gıda mühendisliği vb.) savuşturulmuş olması bunun sonsuza kadar geçerliliği anlamına gelmez. Stokstad (2005), Malthus yanılmış olmaya devam mı edecek? (Will Malthus continue to be wrong?) başlıklı yazısında artan nüfus ve tüketimin politik ve toplumsal açmazlarından bahsederek Malthus'un önermelerini bir kez daha sorgulamıştır. Malthus'un fikirleri yaşanan birçok toplumsal sorunla yeniden canlanmaktadır. Yeni-Malthusçu akım kendini akademik çalışmalarda da yer bulmaktadır (Aligica, 2009; Linnér, 2003). Bu noktada Malthus'un önermeleri ve görüşleri turizm alanında da değerlendirilebilir. 


\section{Turizm ve Malthus'un Sinırı}

Nüfus-Besin ikilemi ve ilişkisine dair soru temel olarak devamlılığın konusudur. Bu konu insan toplumunun varlığını ne ölçüde ve hangi sınırlarla devam ettirebileceğini tartışmaktadır. Benzer bir sorunun, turizm hareketleri ve turizm durakları için de düşünülmesi gereklidir. Ceron ve Dubois (2007) gibi akademisyenler gelecekte turizm talebi ve sürdürülebilirliğine ilişkin öngörü çalışmaları yapmaktadır. Turizm duraklarının fiziksel, ekolojik ve psikolojik taşıma kapasiteleri mevcuttur ve sınırsız kapasiteleri mevcut değildir. Önceki bölümde paylaşılan Grafik 1 ve 2'ye bakıldığında uluslararası ziyaretçi artışı oranı ve miktarı görülebilir.

Uluslararası turistik ziyaretçi sayısının artışın 1983 'ten bu yana olan ortalaması alındığında yıllık \%4.7 artış olduğunu görmekteyiz. 1983 yılında 277 milyon ile başlayan aynı verinin, 2018 yılında 1407 milyona ulaştığı görülmektedir. 1.4 milyarlık ziyaret sayısının, geçmiş yıllardaki artış ve teknolojik gelişmeler göz önüne alınarak yükselişini sürdüreceği kolayca öngörülebilir. Bu durumda nüfus artışı da turistik ziyaretler de artış göstermektedir (Grafik 4).

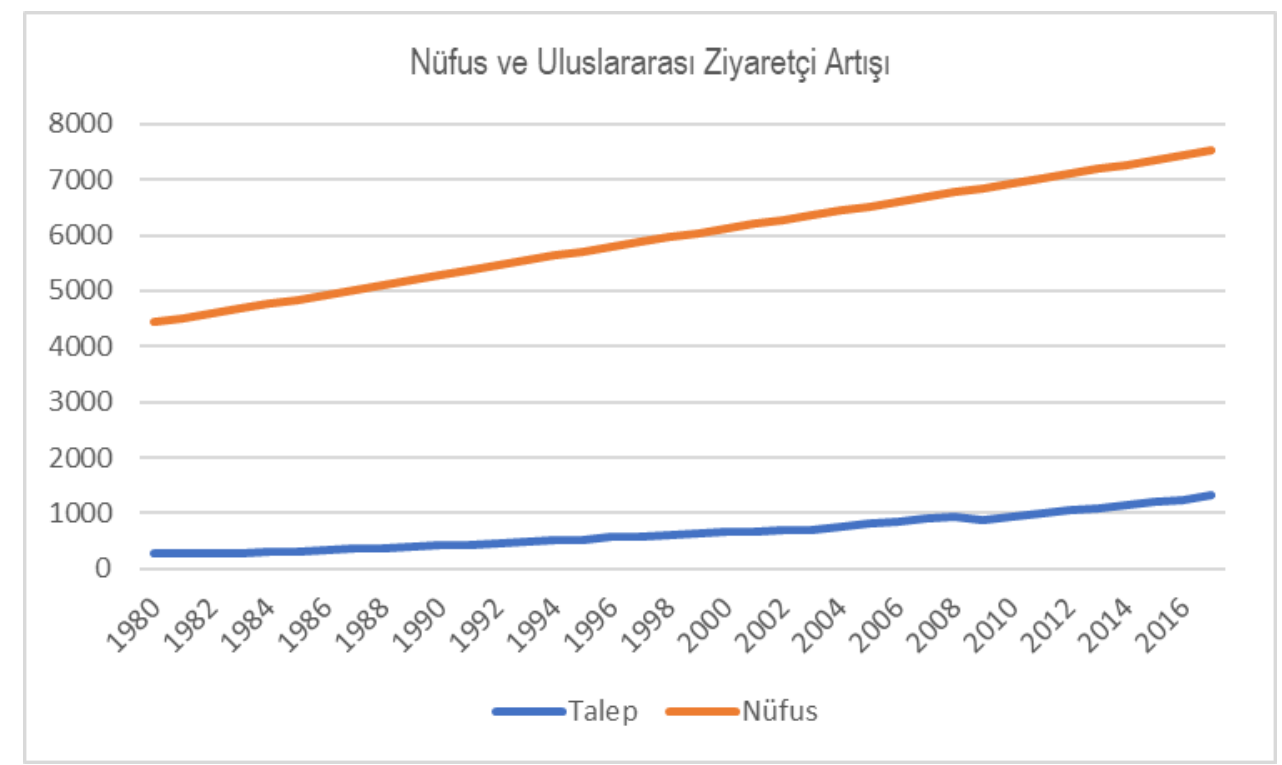

Grafik 4. Nüfus ve Uluslararası Ziyaretçi Artışı (Dünya Bankası. (2020). Dünya kalkınma göstergeleri - google halka açık veriler gezgini.

https://www.google.com/publicdata/explore?ds=d5bncppjof8f9_\&met_y=sp_pop_totl\&hl=tr\&dl=tr adresinden 21.09.2020 tarihinde erişilmiştir ve United Nations World Tourism Organization. (2020).

Global and regional tourism performance | UNWTO. https://www.unwto.org/global-and-regionaltourism-performance adresinden 21.09.2020 tarihinde erişilmiştir.)

Öyleyse nüfus artışı sadece enerji, toprak ve besin gibi kaynaklara değil turizme yönelik talebinde temelindedir. Malthus'un sınırı nüfus için besin üretimidir, turizm için ise bu talep turizm durakları ve doğa bilimdir. Dünya'daki her insanın ortalama bir batılı standartlarında yaşayabilmesi kaynaklar düşünüldüğünde mümkün değildir. Öyleyse turizm için de aynı durum geçerli midir?

\section{Sonuç, Tartışma ve Öneriler}

Araştırma neticesi üç temel kavramın bir döngü içinde olduğu görülmüştür. Bunlar nüfus artış1, turizm talebi ve doğal kaynaklar. Bu üç kaynak bir çember şeklinde birbirini takip ederken çemberin aşamalarında girdileri ve çıktıları vardır (Şekil 1). 

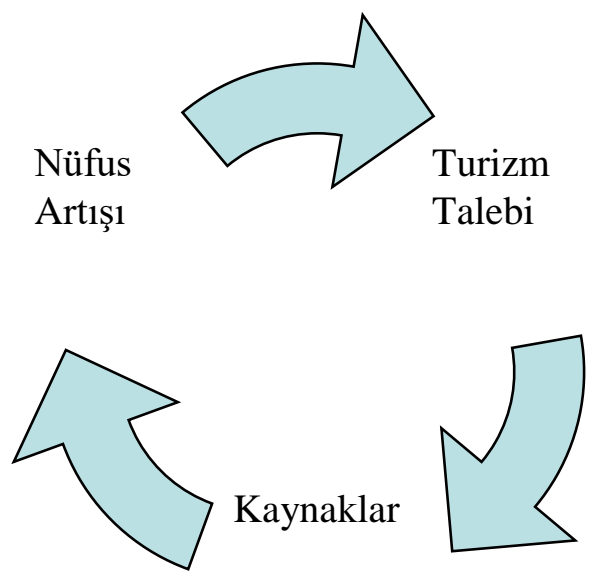

\section{Şekil 1. Döngü}

Nüfus artışı artan tüketimin başlıca nedenir. İnsanlar bireysel olarak tüketimlerini kıssalar bile toplam sayılarının artması tüketimi kaçınılmaz hale getirir. Nüfus arışı ise temel gıda kaynaklarının üretimine paraleldir ki Malthus, nüfus artışının üst sırını olarak besin üretim miktarını çizmektedir. Nüfus artışını besleyen gıda aynı zamanda onun sınırlarını oluşturur.

Turizm talebi artışı döngünün ikinci aşamasıdır. Nüfus artışı, sanayi devrimi, teknolojik yenilikler, altyapı ve üstyapıdaki gelişmeler, ulaşım ve ağırlama gibi sektörlerin gelişmesi turizm davranışı için uygun imkân sağlar. Bu aşamanın girdisi kapasitedir. Taşıma kapasitesi turizmi mümkün kılar ve aynı besinin nüfusa sunduğu genişleme alanına benzer şekilde turizme genişleme alanı sunar. Turizm talebinin artışını besleyen kapasiteler aynı zamnda onun sınırlarını oluşturur.

Kaynaklar döngünün üçüncü ama başlangıç aşamasıdır. Aslına bakılırsa kaynaklar tüm bahsi geçen çember için temel oluşturur ve döngünün başlamasına imkân verir. Aşırı turizmi çözmek için alanyazında önerilen çözümler bu aşamada başarısızlığa uğramaktadır. Çünkü turizm talebi başka turizm duraklarına kaydırılsa da sınırlı olan doğal kaynakları tüketecektir. Doğal kaynaklar için girdi keşifler (doğalgaz, doğal güzellikle ve imkanlar vb.) ve kullanıma açılmalar (hali hazırda var olan ormanların tahribatı, yeni alanların yerleşime açılması vb.) şeklinde gerçekleşir. Çıktı da bunların kullanımı ve azalmasıdır. İnsanlar çevreci endişelerle tüketimlerini bireysel olarak kıssalar bile bunlar artan insan sayısı, gelişmekte ve az gelişmiş ülkelerdeki insanların da gelişmiş ülkelerdeki bireyler gibi yaşamak istemesi kaynaklardan çıktıyı giderecek artıracaktır. Bu, döngüde sorun olduğu anlamına gelir. Çünkü sonunda belirli doğal sınırlamalarla kesintiye uğrayacaktır.

Malthus'un nüfus teorisi birçok açıdan eleştirilere maruz kalmıştır. İnsanlık teknolojik gelişmeler sayesinde besin üretimini sürekli katlarken nüfusundaki artış hızı da düşmektedir. $\mathrm{Bu}$ gelişmeler onun öngörülerini birçok kez haksız çıkarmıştır. Ancak bu nüfus artışının durduğu anlamına gelmediği gibi gelecek insanlığın kıtlık, besin, enerji sorunu ile karşılaşmayacağı anlamına gelmemektedir. Nüfus artmaya devam ettikçe daha fazla gereksinim ortaya çıkacaktır, tüketiciliğin hızla artması gereksinimleri daha da katlarken birçok gelişmekte ve az gelişmiş olan ülke gelişmiş ülkelerdeki yaşam standartlarını yakalamak için daha da çalışacaktır. Bu durum Malthus'un önermesindeki sınırın gerçekten aşılması anlamına gelebilir. Öyleyse benzer bir durum turizm için de birçok açılardan değerlendirilebilir.

Turizm hem yerel hem de ulusal hükümetler tarafından sürekli tanıtımlarla teşvik edilmektedir. Bunun yanı sıra birçok özel kuruluş (düşük maliyet havayolları, Airbnb ve Eatwith tarzı şirketler) kendi tanıtımlarıyla çalıştıkları turizm duraklarına, yerleşim bölgelerine turist çekmeye ve müşteri kazanmaya çalışmaktadır. Ancak şu an bile birçok Avrupa turizm durağ 1 tolerans sınırını aşmıştır. Durakların taşıma kapasitesi zorlanmaktadır. Daha genel bir resimden bakıldığında ise havayolu gibi dünya turizmin sık kullanılan ulaşım araçları en çok karbon salınımına ve gürültü 
kirliliğine sebep olan araçlardandır. Dünya'da turizm talebinin büyümesi bunların kullanımını da kaçınılmaz olarak etkileyecektir. Fakat ne hali hazırda kalabalık olan turizm kentleri sınırsız sayıda turist kabul edebilir, ne de dünya bu kadar çok karbon salınımının altından kalkabilir. Turizmin bir ikilemi olduğu gözükmektedir veya bir ikilem içinde olduğu söylenebilir.

Çalışmanın çıkarımı olarak turizmde artan talep ve ziyaretçi sayısı karşısında tepkisiz kalınması halinde turizm duraklarının yavaş yavaş yereller tarafında terk edilerek turist çoğunluğun kullanıma bırakılmış "turist parkları" haline gelmesi kaçınılmazdır. Soruna tepki için ise ya çeşitli sınırlamalar getirilmek durumunda kalınacak (ziyaretçi kotası, turist vergileri vb.), ya da bu talep başka turizm duraklarına yönlendirilmek durumunda kalınacaktır. Bahsedilen ikinci seçenek aşırı turizmi başka alanlara kaydırmak anlamına gelmektedir. Yani yeni turizm durakları yaratılacak veya olanlar büyütülecek. Fakat bu daha fazla doğal kaynak ve ekonomik imkânın kullanımı anlamına gelmektedir ki bunun da doğal kaynaklar üzerinde sınırı vardır. Diğer bir etken de alternatif maliyet olacaktır, turizm yatırımlarının verimliliği sosyal ve ekonomik faydaları sorgulanacaktır ve sorgulanmalıdır. Öyleyse Malthus benzeri bir sınır turizm faaliyetleri için de mevcut olabilir. Öyle bir sınır mevcut olabilir ki bu sınırı geçip daha fazla ziyaretçi kabul etmek mümkün olmayacaktır. Bu noktada küçülme(degrowth) mümkün olan tek çözüm olarak gözükmektedir. Mümkün olanın, sınırın, esnemeye zorlanması durumunda ise çevresel, ekonomik ve toplumsal sorunların ortaya çıkması kaçınılmazdır. Turizmde sürdürülebilirlik kavramı ise nihayetinde kaçınılmaz olanın ertelenmesi olarak anlaşılabilir.

\section{Yazarların Katkı Oranı}

Bu makaleye birinci yazarın \%70, ikinci yazarın \%30 oranında katkısı vardır.

\section{Çıkar Çatışması}

Bu çalışmada çıkar çatışması teşkil edebilecek bir durum yoktur.

Açıklamalar: Bu çalışmaya ilişkin genişletilmiş özeti International Travel and Tourism Dynamic (ITTD20) kongresine gönderilmiştir ve aynı kongrede genişletilmiş özet olarak yayınlanmış ve çevrimiçi sunumu yapılmıştır. Tam metin genişletilmiş özet temelinde olmakla birlikte değiş̧iklikler ve yeni tartışmalar içermektedir.

\section{Kaynaklar}

Aligica, P. D. (2009). Julian Simon and the "Limits to growth" Neo-Malthusianism. The Electronic Journal of Sustainable Development, 1(3), 49.

Avond, G., Bacari, C., Limea, I., Seraphin, H., Gowreesunkar, V. and Mhanna, R. (2019). Overtourism: a result of the Janus-faced character of the tourism industry. Worldwide Hospitality and Tourism Themes, 11(5), 552-565. doi: 10.1108/WHATT-06-2019-0039.

Bourliataux Lajoinie, S., Dosquet, F. and del Olmo Arriaga, J. L. (2019). The dark side of digital technology to overtourism: the case of Barcelona, Worldwide Hospitality and Tourism Themes, 11(5), 582-593. doi: 10.1108/WHATT-06-2019-0041.

Buluk, B. ve Eşitti, B. (2019). Batıdan doğuya yavaş seyahat: Doğu ekspresinin Kars'ın sürdürülebilir turizm gelişimine etkisi. Ahi Evran Üniversitesi Sosyal Bilimler Enstitüsü Dergisi, 5(2), 159176. doi: 10.31592/aeusbed.571083

Butler, R. W. (1980). The concept of a tourist area cycle of evolution: implications for management of resources. Canadian Geographer/Le Géographe canadien, 24(1), 5-12. doi: 10.1111/j.15410064.1980.tb00970.x. 
Caldwell, J. C. (1998). Malthus and the less developed world: the pivotal role of India. Population and development review, 675-696.

Ceron, J. P. and Dubois, G. (2007). Limits to tourism? A backcasting scenario for sustainable tourism mobility in 2050. Tourism and Hospitality, Planning and Development, 4(3), 191-209. doi: 10.1080/14790530701736598.

Çetin, İ. (2017). Yeni gelişen turistik destinasyonlar ve Van'ı ziyaret eden İranlı turistlerin özellikleri. Ahi Evran Üniversitesi Sosyal Bilimler Enstitüsü Dergisi, 3(1), 44-59.

Çetinkaya, G. ve Dedemen, O. (2013). Golf turizmine yönelik yerel halkın algılarının belirlenmesi: Antalya/Belek örneği. Turar Turizm ve Araştırma Dergisi, 2(1), 24-45.

Corry, B. A. (1959). Malthus and Keynes--A reconsiderastion. The Economic Journal, 69(276), 717724.

Dodds, R. and Butler, R. (2019a). Overtourism: Issues, realities and solutions (Vol. 1). Walter de Gruyter GmbH \& Co KG.

Dodds, R. and Butler, R. (2019b). The phenomena of overtourism: A review. International Journal of Tourism Cities, 5(4), 519-528. doi: 10.1108/IJTC-06-2019-0090.

Doxey, G. V (1975). Theory of visitor-resident irritants, methodology and research inferences: the impact of tourism, in sixth annual conference of the travel research association. San Diego, USA.

Dünya Bankası. (2020). Dünya kalkınma göstergeleri - google halka açık veriler gezgini. Erişim adresi https://www.google.com/publicdata/explore?ds=d5bncppjof8f9_\&met_y=sp_pop_totl\&hl=tr\& $\mathrm{dl}=\mathrm{tr}$

Duvick, D. N. (1999). Feeding the ten billion: Plants and population growth. Crop Science, 39(5), 1522-1523. doi: 10.2135/cropsci1999.0002br.

Deutsche Welle. (2018). Venice installs turnstiles to limit massive tourist flow. Erişim adresi https://www.dw.com/en/venice-installs-turnstiles-to-limit-massive-tourist-flow/a-43578659

Goodwin, H. (2017). The challenge of overtourism. Responsible tourism partnership, 4, 1-19.

Jacobsen, J. K. S. and Munar, A. M. (2012). Tourist information search and destination choice in a digital age. Tourism management perspectives, 1, 39-47.

Koens, K., Postma, A. and Papp, B. (2018). Is overtourism overused? Understanding the impact of tourism in a city context. Sustainability, 10(12), 4384. doi: 10.3390/su10124384.

Linnér, B. O. (2003). The return of Malthus: Environmentalism and post-war population-resource crises. UK: White Horse Press.

Malthus, T. R. (2017). Nüfus ilkesi. (Çev. Ç. Taşkın). İstanbul: Pinhan Yayıncılık.

Milano, C., Cheer, J. M. and Novelli, M. (Ed.). (2019). Overtourism: Excesses, discontents and measures in travel and tourism. CABI.

Nepal, R. and Nepal, S. K. (2019). Managing overtourism through economic taxation: policy lessons from five countries. Tourism Geographies, 1-22. 
Page, S. (2011). Tourism management, an introduction 4th edition. Oxford, UK: Elsevier Ltd.

Perkumiené, D. and Pranskūnienè, R. (2019). Overtourism: Between the right to travel and residents' rights. Sustainability, 11(7), 2138.

Price, D. (1998). Of population and false hopes: Malthus and his legacy. Population and Environment, 205-219.

Roncak, M. (2019). 11. Prague and the impact of low-cost airlines. In Overtourism (pp. 152-168). De Gruyter Oldenbourg.

Sæpórsdóttir, A. D., Hall, C. M. and Wendt, M. (2020). From boiling to frozen? The rise and fall of international tourism to Iceland in the era of overtourism. Environments, 7(8), 1-19. doi:10.3390/environments7080059.

Sigala, M., Rahimi, R. and Thelwall, M. (Ed.). (2019) Big Data and Innovation in Tourism, Travel, and Hospitality. Springer

Sky News. (2018). Venice installs gates to limit tourist numbers. Erişim adresi https://news.sky.com/story/venice-installs-gates-to-limit-tourist-numbers-11350585

Smith, P. (2015). Malthus is still wrong: we can feed a world of 9-10 billion, but only by reducing food demand. Proceedings of the Nutrition Society, 74(3), 187-190.

Stokstad, E. (2005). Will Malthus continue to be wrong?. Science, 309(5731), 102-102.

T.C. Kültür ve Turizm Bakanlığı (2013). Türkiye Turizm Stratejisi 2023 Eylem Planı 2007 - 2013. Erişim adresi https://www.ktb.gov.tr/Eklenti/906,ttstratejisi2023pdf.pdf?0

Trewavas, A. (2002). Malthus foiled again and again. Nature, 418(6898), 668-670.

Uğur, A. A. ve İzgi, B. B. (2011). Küreselleşme sürecinde geçiş ekonomilerinin sosyo-ekonomik adaptasyonu. Elektronik Sosyal Bilimler Dergisi, 10(38), 158-174.

United Nations World Tourism Organization. (2020). Global and regional tourism performance. Erişim adresi https://www.unwto.org/global-and-regional-tourism-performance

Wrigley, E. A. (1988). The limits to growth: Malthus and the classical economists. Population and Development Review, 14, 30-48. doi: 10.2307/2808089.

Yılmaz, Ö. D. ve Filiz, A. (2017). Turizm gelişim yaklarşımları kapsamında yerel halkın turizme yönelik alg1 ve tutumları: Mazi Köyü-Türkbükü karşılaştırmalı analizi. Hitit Üniversitesi Sosyal Bilimler Enstitüsü Dergisi, 10(2), 1799-1824. 


\section{Extended Abstract}

\section{Introduction}

The problem of over-tourism is persistent and tends to increase (Dodds and Butler, 2019a). That tendency is parallel to the persistence of demand. Although the demand for tourism and the problems caused by tourists have already existed, these problems have turned into constant problems, making it a known phenomenon for all tourism stops. It creates a dilemma when trying to solve it through the expansion and expansion of extreme tourism stops and the creation of new ones because the demand is still present. Population growth and the problems caused by it can be considered in parallel with the problems caused by the increase in tourism demand.

The Malthusian theory is based on the relationship between population and food production. According to Malthus (2017), food growth will feed the growing human population, and population growth will make food production neccesary to feed people. However, it is impossible for this to continue forever, because Earth's resources are limited. Over-tourism and Malthus's population theory lead to similar predicaments. It is unthinkable that both food production and tourism destinations and their capacity will increase forever. On the contrary, after a point, increases will damage the resources that feed them, the natural and economic system, and ultimately the population. Due to these similarities, this conceptual study aimed to deal with population growth, participation in tourism and excessive tourism problem within the scope of Malthus' population theory.

\section{Tourism Destionation and Overtourism}

Due to the economic benefits of tourism, tourism destination management bodies aimed to increase the number of tourists and maximize their revenues instead of managing tourism (Dodds and Butler, 2019b, p. 521). As a result of this way of thinking, the number of tourists has increased and incomes have also increased in parallel. However, the problems that come with them have generally been ignored. Solution suggestions in the literature can be listed as follows:

- Reduction (demotion)

- Setting limitation

- Deterrence and barrier

- Distributing the density, directing tourists to less intense tourism stops

However, the solution proposals aim to stop the problem temporarily, to postpone it by distributing it to other areas, or to limit the overcrowding that creates dissatisfaction within the destinaiton, rather than solving overtourism. The suggested solutions are an indication that the existence of the problem is permanent. The recommendations are far from eliminating the problem of overtourism.

\section{Principle of Population and Malthus}

Malthus' controversial principle is based on the following assumptions (Malthus, 2017, p. 29):

- Nutrition is essential for human existence.

- Passion between sexes is essential and will remain almost the same in the future.

Based on these assumptions, he proposes that the rate of increase in the population of humanity will gradually multiply the increase in the amount of food production and will eventually enter an impasse. When it comes to an exact limit, food and population will be on par. However, when this limit, which is called the limit of Malthus, is exceeded, the food will be no longer sufficient (Graphic 3). Therefore, the parallel progress of these two (growth of both population and food production) is not possible for a long time. The total food population produced at some point will not 
be enough to feed. If wars, conflicts, social turmoil and diseases cannot reduce the human population after the border is crossed, famines will cause people to die.

\section{Malthusian Catastrophe, Limit and Tourism}

Population growth is source of tourism demand as well as resources such as energy, soil and food. The limit of Malthus is food production for the population, while the limit for tourism is number of destionations, their capacities and nature sciences and their rules. Considering the resources, it is impossible for every person in the world to live at an average western standard. So, is the same for tourism?

As a result of the our deliberation, it was seen that three fundemental elements are in a cycle. These are population growth, tourism demand and resources. While these three sources follow each other in a circle, the stages of the circle have inputs and outputs (Figure 1).
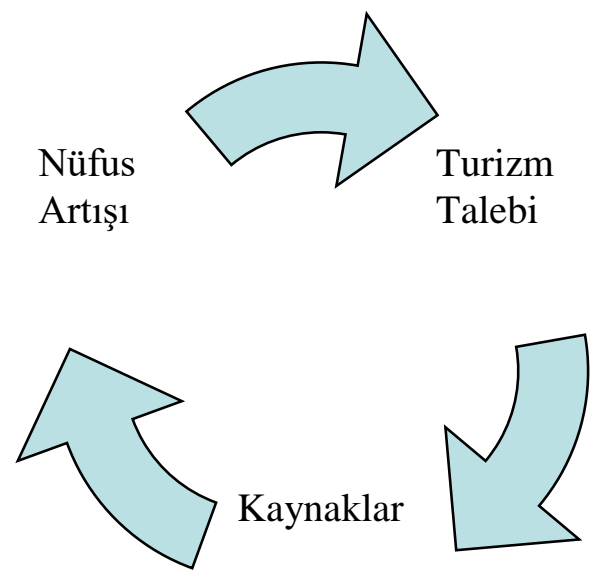

Figure 1. Cycle

Population growth is the main cause of increasing consumption. Even if people reduce their consumption individually, the increase in their total amount of consumption is inevitable. Population growth is parallel to the production of food, and Malthus draws the amount of food production as the upper limit of population growth. Food that feeds population growth also draws its boundaries.

Tourism demand growth is the second stage of the cycle. Population growth, industrial revolution, technological innovations, infrastructure and superstructure developments, transportation and hospitality provide appropriate conditions for tourism behavior. The input of this stage is capacity. For example carrying capacity, enables tourism and presents to tourism an expansion space for future similar to the area of expansion presented by the food to the population growth. The capacities that feed the growth of tourism demand also draws its limits.

Resources are the third but, initial and last stage of the cycle. In fact, the resources are fundemental for the entire cycle and allow the cycle to begin. The solutions proposed in the literature to solve overtourism fail at this stage. Even if the demand for tourism is shifted to other destinations, it will consume limited natural resources. It takes place in the form of discovery of inputs for natural resources (natural gas, nature and wilderness.) and opening to use (destruction of existing forests, opening of new areas for new urban areas or agriculture etc.). The output is their use and reduction. Even though, people who have environmental concerns limits their consumption individually, there are increasing number of people in the World. Moreover people in developing and less developed countries want to live like individuals in developed countries. That means there is dilemma in cycle. It will be eventually be interrupted by certain natural limitation. 


\section{Conclusion, Discussion and Recommendations}

As the result of the study, in case of unresponsiveness to the increasing demand in tourism, overtourism and the number of visitors, it is inevitable that tourism destinaiton will gradually be abandoned by the locals and become "tourist parks" which is left for the use of the tourists in general. In order to react to the problem, various restrictions can be imposed (visitor quota, tourist taxes, etc.) or this growing tourist demand will have to be directed to other tourism destinations. But that second option means shifting, directing overtourism to other areas. In other words, new tourism destinations will be created or the ones which have been already exist will be enlarged. But this means the use of more natural resources and economic capacity, which have a limit on Earth. Tourism is in a dilemma or has a dilemma. Another problem is alternative costs, the efficiency of tourism investments, social and economic benefits will be questioned and should be questioned. Creating new tourism destination will be a good investment for humankind? So, a Malthusian limit may also be available, exist for tourism activities. There can be an exact limit that it can not be possible to cross this limit and take more visitors. if we force that limit to be stretched, it is inevitable that environmental, economic and social problems will be arise. The concept of sustainability in tourism will ultimately be challenged by realities of the nature and sustaininability will be changed its meaing as postponement. 